\title{
Highway Tollbooth Worker
}

Ryan Childers, MD

Division of Gastroenterology, Oregon Health and Science University, Portland, OR, USA.

Ten o'clock hits, and I am nestled.

Thermos, newspaper, radio,

Pictures of my wife, my kids

Dog-eared and taped to the glass.

Midnight; traffic becomes lighter.

A few gulps of coffee help

Wash my heart pills down.

Doc said "Take "em at bedtime"

But when you work a double,

You sometimes forget.

Two o'clock comes; the night whispers.

I turn up the radio

Against the chill of the winter air

And the stillness of this highway.

Funny beats in my chest_-it's just the coffee.

Four o'clock glides; the night is long.

My legs are heavy, cramped;

The sweet surrender of sleep

Beckons like the soft hoot

Of a barn owl, or the horn of a barge

On some cold, black water nearby.

Six o'clock settles; the dawn quietly peeks.

Notes of sweetness arrive

On the crisp morning breeze

And my heart, now steady,

Lifts and soars; my soul warms

With thoughts of home.

Corresponding Author: Ryan Childers, MD, Division of Gastroenterology, Oregon Health and Science University, Mailcode L461, 3181 SW Sam Jackson Park Road, Portland, OR 97239, USA (e-mail: childerr@ ohsu.edu).

$J$ Gen Intern Med 29(1):261

DOI: $10.1007 / \mathrm{s} 11606-013-2558-2$

(c) Society of General Internal Medicine 2013 